\title{
PACTEL and PWR PACTEL Test Facilities for Versatile LWR Applications
}

\author{
Virpi Kouhia, Heikki Purhonen, Vesa Riikonen, Markku Puustinen, \\ Riitta Kyrki-Rajamäki, and Juhani Vihavainen
}

LUT Energy, Lappeenranta University of Technology, P.O. BOX 20, 53851 Lappeenranta, Finland

Correspondence should be addressed to Heikki Purhonen, heikki.purhonen@lut.fi

Received 19 May 2011; Accepted 14 September 2011

Academic Editor: Klaus Umminger

Copyright (C) 2012 Virpi Kouhia et al. This is an open access article distributed under the Creative Commons Attribution License, which permits unrestricted use, distribution, and reproduction in any medium, provided the original work is properly cited.

\begin{abstract}
This paper describes construction and experimental research activities with two test facilities, PACTEL and PWR PACTEL. The PACTEL facility, comprising of reactor pressure vessel parts, three loops with horizontal steam generators, a pressurizer, and emergency core cooling systems, was designed to model the thermal-hydraulic behaviour of VVER-440-type reactors. The facility has been utilized in miscellaneous applications and experiments, for example, in the OECD International Standard Problem ISP33. PACTEL has been upgraded and modified on a case-by-case basis. The latest facility configuration, the PWR PACTEL facility, was constructed for research activities associated with the EPR-type reactor. A significant design basis is to utilize certain parts of PACTEL, and at the same time, to focus on a proper construction of two new loops and vertical steam generators with an extensive instrumentation. The PWR PACTEL benchmark exercise was launched in 2010 with a small break loss-of-coolant accident test as the chosen transient. Both facilities, PACTEL and PWR PACTEL, are maintained fully operational side by side.
\end{abstract}

\section{Introduction}

Since 1976, thermal-hydraulics of nuclear power plants has been studied experimentally at Lappeenranta University of Technology (LUT). During the years, several experiment facilities have been built to study the behaviour of light water reactors. Experimental work with the separate effect test facilities and the large integral test facility has generated a wide data base containing about 900 experiments. Along the years the cooperation with Technical Research Centre of Finland (VTT) induced the decisions to build many of the test facilities utilized at LUT, including the largest one, that is, the parallel channel test facility (PACTEL), described in [1-4].

In Finland, in addition to international cooperation, own research and continuous development of know-how has always been part of the national nuclear safety concept, especially when connected with the specific nuclear power plant types operated in Finland. Hence, the PACTEL facility was constructed in 1990 to have a large-scale test facility available for studies of thermal-hydraulics of a VVER-440 type nuclear power plant. The two units of the Loviisa power plant in
Finland are of this type. PACTEL has been utilized in several versatile experimental applications along the years as presented, for example, in [1].

As a new EPR-type pressurized water reactor (PWR) is under construction in Olkiluoto in Finland, national research activities on PWR behaviour are being intensified. The new PWR PACTEL facility, a modified version of the original PACTEL facility, has been introduced in order to stimulate research activities on PWR and EPR specifics. PWR PACTEL shares some parts with PACTEL but includes several completely new parts to fulfil the specific facility research purposes. As the original PACTEL facility is also maintained, both PACTEL and PWR PACTEL are fully operational at the moment, as discussed in $[5,6]$.

This paper includes a description of the PACTEL facility setup and a presentation of specific facility characteristics. The experimental work with PACTEL is introduced through a short review of some chosen research cases. In particular, the OECD International Standard Problem ISP-33, based on one of the PACTEL natural circulation experiments, is presented. The latter part of this paper introduces the PWR PACTEL facility setup and specific characteristics connected 
to it. The ongoing PWR PACTEL benchmark exercise case is presented concisely, as through the exercise the first experiment results with this new facility concept are published.

\section{PACTEL}

2.1. PACTEL Facility Description. The PACTEL facility is a $1: 305$ volumetrically scaled, out-of-pile, full height model of a six loop Russian design VVER-440 type PWR. The reference reactor for PACTEL is the Loviisa VVER-440 reactor in Finland. PACTEL includes pressure vessel parts, three primary loops with horizontal steam generators, a pressurizer, and an emergency core cooling system (ECCS). The pressure vessel model is of U-tube shape modelling the downcomer, lower plenum, active core, and upper plenum. The system component heights and elevations have been preserved to simulate gravity dominated natural circulation flow processes correctly. The original facility description is made available by Tuunanen et al. in [4] and presented also by Purhonen et al. in [1-3]. Some of the PACTEL facility characteristics compared with the reference reactor are shown in Table 1. PACTEL in the laboratory site is shown in the photograph in Figure 1, and a schematic view of the facility can be seen in Figure 2.

The core rod bundle of PACTEL consists of 144 electrically heated fuel rod simulators. The outer diameter of the simulators is $9.1 \mathrm{~mm}$ and the thickness of the stainless steel cladding is $0.9 \mathrm{~mm}$. The rods are fixed in a triangular grid, with a lattice pitch of $12.2 \mathrm{~mm}$. The fuel rod simulators are organized in three parallel channels that each includes 48 rods. All the rods have a nine-step chopped cosine axial power distribution. The axial peaking factor is 1.4, and the total heated length is $2420 \mathrm{~mm}$. The number and construction of the rod spacers are identical to the reference reactor. The core is powered by a $1 \mathrm{MW}$ electric power supply. This is $\sim 22 \%$ of the scaled thermal power (originally $1375 \mathrm{MW}$ ) of the reference reactor. Different power levels can be used in the three separate core channels. Diffusers are installed in the hot and cold leg connections to prevent direct ECC water flow to the loops. There is no bypass from the upper plenum to the downcomer in the facility.

PACTEL has three almost symmetric equal volume primary loops and each of these models two loops of the reference reactor. Froude scaling, together with volumetric scaling, was the main design principle in selecting the pipe dimensions of the facility hot and cold legs. Together these two scaling methods result in larger diameter and in about $50 \%$ shorter hot and cold legs than in the reference reactor. Larger diameter pipes lead to better simulation of flow regime transitions in the horizontal parts of the loops. The use of volumetric scaling has an effect on the pressure loss distribution around the loops. Also, the relative volume of loop seals is larger than in the reference plant.

Each loop has a horizontal steam generator with heat exchange U-tubes, a primary cooling pump, and a loop seal both in the hot and cold legs. The horizontal steam generators as well as the hot leg loop seals are a unique feature of the VVER-440 design. In the current steam generators of

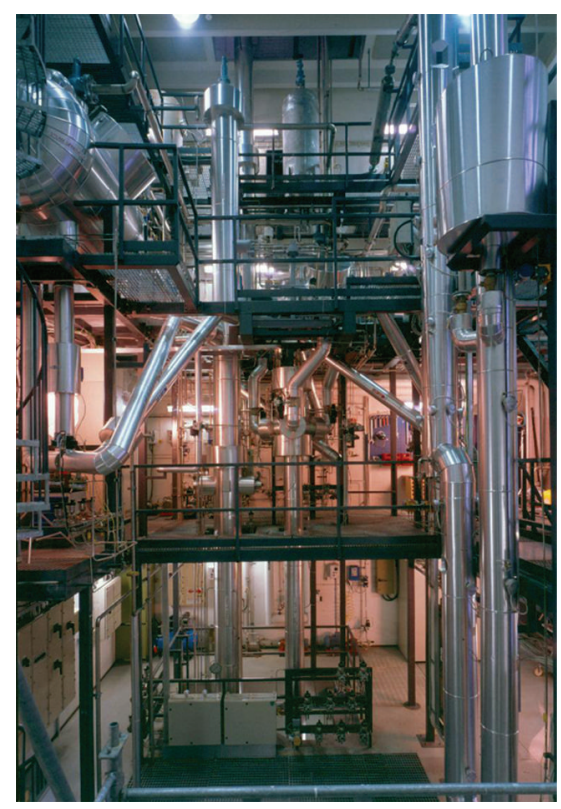

Figure 1: PACTEL facility in laboratory.

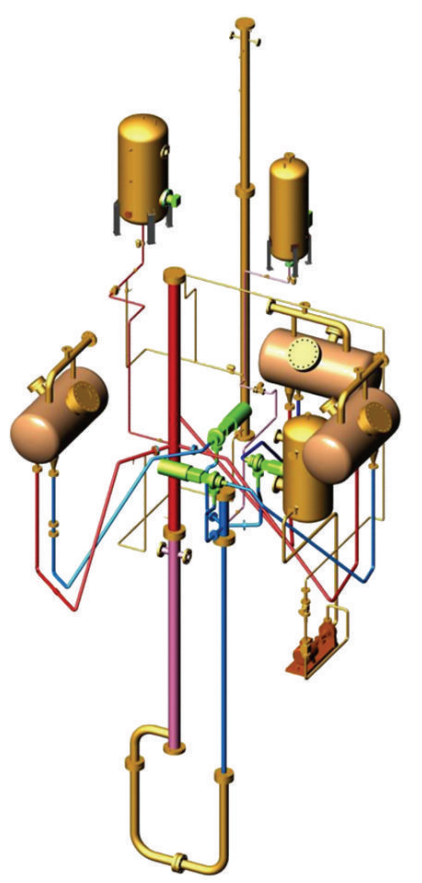

Figure 2: Schematic view of PACTEL.

PACTEL, the average length of the heat exchange tubes is about $3 \mathrm{~m}$ and the diameter of the steam generator shell is $1.0 \mathrm{~m}$. The diameter of the tubes $(16 \times 1.5 \mathrm{~mm})$ is the same as in the reference plant, but the vertical distance between the tube rows is doubled to get the height of the PACTEL steam generator closer to that of the reference steam generator. The earlier first-generation horizontal steam generators of PACTEL were of a different design. The average length of the heat exchange tubes was about $8.5 \mathrm{~m}$, and the diameter of the steam generator shell was smaller $(0.4 \mathrm{~m})$ than in the current 
TABLE 1: PACTEL facility characteristics and comparative reference reactor values.

\begin{tabular}{|c|c|c|}
\hline Characteristic & PACTEL & $\begin{array}{c}\text { VVER-440 } \\
\text { (Loviisa) }\end{array}$ \\
\hline Reference power plant & VVER-440 & - \\
\hline Volumetric scaling ratio & $1: 305$ & - \\
\hline Scaling factor for component heights and elevations & $1: 1$ & - \\
\hline Number of primary loops & 3 & 6 \\
\hline Steam generator type & Horizontal & Horizontal \\
\hline Maximum heating power/thermal power $[\mathrm{MW}]$ & 1 & $1500(1375)$ \\
\hline Number of rod simulators—fuel rods & 144 & 39438 \\
\hline Outer diameter of rod simulators—fuel rods [mm] & 9.1 & 9.1 \\
\hline Rod simulator—fuel rod pitch $[\mathrm{mm}]$ & 12.2 & 12.2 \\
\hline Heated length of rod simulators—fuel rods [m] & 2.42 & 2.42 \\
\hline Axial power distribution & Chopped cosine & - \\
\hline Maximum cladding temperature $\left[{ }^{\circ} \mathrm{C}\right]$ & 800 & - \\
\hline Maximum operating pressure [MPa] & 8.0 & 12.3 \\
\hline Maximum operating temperature $\left[{ }^{\circ} \mathrm{C}\right]$ & 300 & 300 \\
\hline Maximum secondary pressure [MPa] & 5.0 & 5.0 \\
\hline Maximum secondary temperature $\left[{ }^{\circ} \mathrm{C}\right]$ & 260 & 260 \\
\hline Feedwater tank pressure $[\mathrm{MPa}]$ & 2.5 & 2.5 \\
\hline Feedwater tank temperature $\left[{ }^{\circ} \mathrm{C}\right]$ & 225 & 225 \\
\hline Accumulator pressure $[\mathrm{MPa}]$ & 5.5 & 5.5 \\
\hline Low-pressure ECC-water pressure [MPa] & 0.7 & 0.7 \\
\hline High-pressure ECC-water pressure $[\mathrm{MPa}]$ & 8.0 & 8.0 \\
\hline ECC-water temperature $\left[{ }^{\circ} \mathrm{C}\right]$ & $30-50$ & $30-50$ \\
\hline Main material of components & Stainless steel & - \\
\hline Insulation material & $\begin{array}{c}\text { Mineral wool } \\
\text { (Aluminium cover) }\end{array}$ & - \\
\hline
\end{tabular}

design. Yet, the heat exchange U-tube diameter was the same as with the present steam generator U-tubes.

The full-length pressurizer is connected to the hot leg of loop one. The pressurizer is made of two equal diameter parts one above the other, joined with flanges. Heating and spray systems have been attached to the pressurizer. The total height of the pressurizer is $8.8 \mathrm{~m}$.

The system component heights and elevations have been preserved to simulate gravity-dominated natural circulation flow processes correctly. In scaled down facilities, not all thermal-hydraulic phenomena necessarily occur in the same way and order as in the reference systems. Despite of preserving component heights and elevations in PACTEL, other factors lead to scaling distortions. Heat losses and the amount of energy stored in the structures are in scaled test facilities different from those of the systems that they are simulating.

The basic instrumentation of PACTEL consists of thermocouples, pressure and differential pressure transducers, and flow meters. The temperature measurements include rod cladding, structure wall and coolant as well as reference temperature measurements. There are two pressure measurements in the primary side, the first one in the upper plenum and the second one at the top of the pressurizer. Secondary pressures are measured in discharge steam line in each steam generator. There are 43 differential pressure transducers in PACTEL, mainly used to determine liquid levels in different parts of the primary circuit and in the secondary sides of the steam generators. Loop flows are measured in the vertical part of each cold leg below the steam generator. The total primary flow is measured in the downcomer. Accumulator and high-pressure injection system flows as well as feedwater flows to each steam generator are also measured. The break flow rate in loss of coolant accident (LOCA) experiments can be measured both directly and indirectly.

2.2. Design Upgrades. During the years, the PACTEL facility has gone through several structural changes due to the different objectives and scaling requirements of the individual test programs. Equipment upgrades dictated by maintenance needs as well as instrumentation and software upgrades to take advantage of the developments in the field of measurements and data acquisition have also been made as presented in $[2,3]$.

As described in Chapter 2.1, PACTEL has introduced already two sets of different steam generators, the original long and narrow ones and the present short and thick ones described by Purhonen et al. in [1-4]. Recently, the core channel construction has also been refurbished and renovated, yet the geometry and core configuration principles 
TABLE 2: PACTEL experiments, examples on performed experiment types.

\begin{tabular}{|c|c|c|}
\hline Experiment type & Specific focuses & Related NPP \\
\hline Small break loss of coolant accident (SBLOCA) & $\begin{array}{l}\text { Natural circulation, steam generator behaviour, feed and } \\
\text { bleed procedures }\end{array}$ & VVER-440 \\
\hline Stepwise coolant inventory reduction (SIR) & Natural circulation, ISP-33 case & VVER-440 \\
\hline Primary to secondary leakage (PRISE) & Multiple-tube rupture & VVER-440 \\
\hline Anticipated transient without scram (ATWS) & $\begin{array}{l}\text { Natural circulation with reduced primary inventory, } \\
\text { maximum pressure while inadvertent control rod withdrawal }\end{array}$ & VVER-440 \\
\hline Pressure and heat loss experiments & Facility characterization & VVER-440 \\
\hline Loss of secondary feedwater (LOF) & Deterioration of heat transfer & VVER-440 \\
\hline Improved accident management (IMPAM) & Starting of depressurization during SBLOCA & VVER-440 \\
\hline $\begin{array}{l}\text { Passive safety injection, core make up tank (CMT) } \\
\text { behaviour }\end{array}$ & Break size and location effect, CMT position effect & APWR \\
\hline Passive heat removal system behaviour & Start up of natural circulation and long term cooling & VVER-640 \\
\hline Thermal stratification & Hot and cold water stratification effect on thermal loads & - \\
\hline Dissolved noncondensable gases & $\begin{array}{l}\text { Effect of noncondensable gases on system thermal-hydraulics } \\
\text { and heat transfer in steam generators }\end{array}$ & - \\
\hline
\end{tabular}

have been maintained. Reconstructions and modifications to the facility setup have been introduced also during various versatile applications, for example, VVER-640-related experiments discussed in references [1-3]. However, the fundamental and original PACTEL construction has been restored each time.

2.3. PACTEL Experiments. As described earlier, PACTEL was originally designed to model the thermal-hydraulic behaviour of VVER-440-type PWRs. Still, the facility has served also in many other purposes. The facility has been modified on a case-by-case basis according to the needs of each configuration and positioning of auxiliary equipment, leading to a versatile use of PACTEL for a large spectrum of thermalhydraulic research, as presented by Purhonen et al. in [13]. The PACTEL facility is ideal for investigating planned recovery procedures during accidents and operational transients. For this purpose, experimental series among others on small break loss-of-coolant accidents, primary-to-secondary leakages, and on anticipated transients without scram have been carried out. The PACTEL natural circulation experiment with stepwise coolant inventory reductions formed the basis for the OECD International Standard Problem (ISP-33) as presented in $[7,8]$. In addition, many other one-phase and two-phase natural circulation tests have been executed as discussed in more detail by Purhonen et al. in [1-3]. Table 2 introduces very shortly some of the main research topics that dealt with the PACTEL experiments, whose total number is more than 200. PACTEL is included also in the OECD NEA's validation matrixes available in references $[9,10]$. The PACTEL experiments have provided valuable data for the validation processes of several codes, such as APROS, RELAP, CATHARE, and TRACE, for example, presented in reference [11].

2.4. Standard Problem ISP-33. The ISP-33 studied natural circulation in the PACTEL facility with stepwise reduced coolant inventories as presented by Purhonen et al. in [1-3]. The ISP-33 is discussed in more detail in $[7,8]$. The PACTEL natural circulation experiment with stepwise coolant inventory reductions formed the basis for the OECD International Standard Problem (ISP-33) dealing with problems found in the ability of the computer codes to model reduced inventory situations correctly. The main goal of the OECD International Standard Problem ISP-33 experiment was to study natural circulation in a VVER plant including several single- and two-phase natural circulation modes. A VVER440-type reactor was addressed for the first time in the framework of the OECD international standard problems.

The general purpose of the ISP-33 test was to produce data for code assessment and development dealing with problems found in the ability of the computer codes to model reduced inventory situations correctly. The large number of participants produced a spectrum of calculation results with different thermal-hydraulic codes. The variation in calculation results showed the importance of comparison to experimental data, of which an example, regarding primary pressure, is presented in Figure 3. Despite of some inaccuracies in the original specifications, ISP-33 proved to be a successful and valuable exercise. The observed discrepancies in the calculation results were easier to investigate than in most ISPs, because the experiment was not excessively complicated, [1].

\section{PWR PACTEL}

3.1. PWR PACTEL Facility Design. The PWR PACTEL test facility has been designed and constructed in 2009 to be utilized in the safety studies related to thermal-hydraulics of pressurized water reactors with EPR-type vertical steam generators. A significant design and construction basis for the PWR PACTEL facility has been the utilization of some parts of the original PACTEL facility. PWR PACTEL consists of a reactor pressure vessel model, two loops with vertical steam generators, a pressurizer, and emergency core cooling 


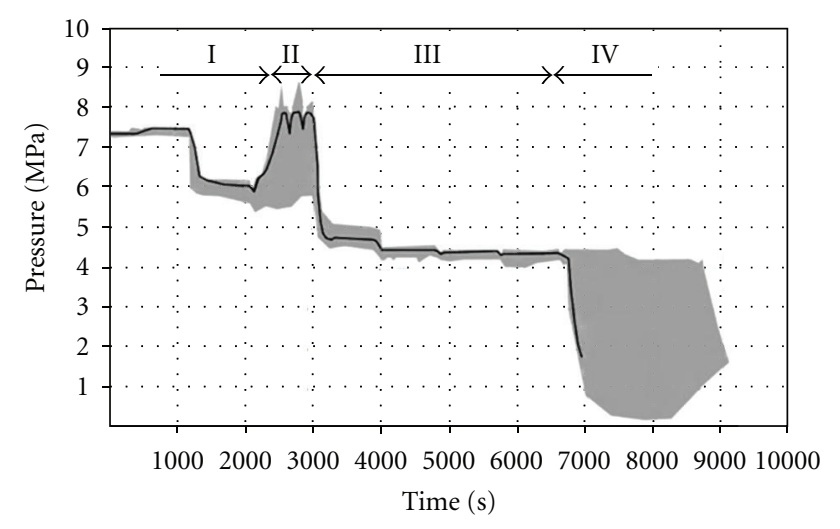

FIgURE 3: Example of ISP-33 results, primary pressure in experiment (solid line) and variation in ISP-33 posttest calculations (gray area). Flow conditions: (I) one-phase flow, (II) flow stagnations, (III) two-phase flow, and (IV) boiler condenser mode, [2] .

systems (ECCSs). The pressure vessel model is comprised of a U-tube construction modelling the downcomer, lower plenum, core, and upper plenum. Figure 4 shows the PWR PACTEL facility. The possibility to use the original PACTEL facility for future needs is preserved. The PWR PACTEL facility is presented in detail by Riikonen et al. in [5] as well as by Rantakaulio et al. in [6].

The heated length of the core is about $2 \mathrm{~m}$ shorter than in the EPR core. However, the centre of the core is at the correct elevation. The maximum core power corresponds roughly to the scaled residual heating power of the EPR reactor. The total height of the PWR PACTEL pressure vessel model corresponds to the pressure vessel height of EPR. The volume ratio between the pressure vessels in PWR PACTEL and EPR is about $1 / 405$. The pressurizer is shorter than in EPR. The volume ratio between pressurizers of PWR PACTEL and EPR is $1 / 562$. The ECCS of PWR PACTEL is basically the same as with PACTEL including high and low pressure pumps and two separate accumulators for injection of water to the downcomer and to the upper plenum. The low-pressure safety injection system can inject water to the downcomer and to the upper plenum. The high-pressure system of PACTEL can be used also in PWR PACTEL, or a new injection point can be installed later for PWR PACTEL.

The main design principle of PWR PACTEL is to focus on the proper construction of the loops and vertical steam generators. The setup of the loops and steam generators is designed to allow simulation of PWR and EPR features and studying loop and steam generator behaviour in particular. The two primary loops with identical vertical steam generators are fully representative for PWR applications. PWR PACTEL has two primary loops, both simulating one reference EPR loop. As there are four primary loops in EPR, half of the rated EPR capacity is simulated with PWR PACTEL. Both of the PWR PACTEL loops have one vertical steam generator. The hot legs with an inner diameter of $52.5 \mathrm{~mm}$ are on the same elevation as the cold legs. The cold legs have loop seals. At present, there are no circulation pumps in PWR PACTEL. However, there are places reserved

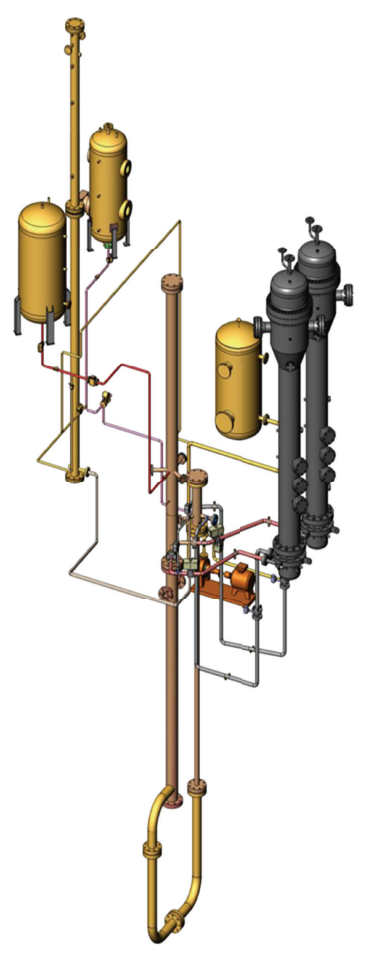

FIgURE 4: PWR PACTEL facility.

in both of the loops for the main circulation pumps for future plans.

Both of the steam generators in PWR PACTEL contain 51 heat exchange $U$-tubes. The average length of the tubes is $6.5 \mathrm{~m}$. The U-tubes are in a triangular grid with a lattice pitch of $27.4 \mathrm{~mm}$. The U-tubes are arranged in five groups according to the lengths, each group containing two rows of tubes. The heat transfer area of the tube bundles and the primary-side volume of each steam generator are scaled down with a ratio of $1 / 400$ compared to the reference steam generator. The inner diameter of the steam generator $\mathrm{U}$ tubes in PWR PACTEL is the same as in the EPR steam generator. The same dimension is important for the correct simulation of CCFL phenomena.

The secondary side of the steam generators includes a downcomer, riser, and steam dome volumes, whereas there are no steam separators. On the other hand, the secondary side is also divided into hot and cold parts. Due to the used manufacturing method, the compartments are not fully water tight. Hence, minor cross flows can occur between the hot and cold parts, and also pressure balancing between the downcomer and steam volume is possible. The water volume of the secondary side is about double compared to the volumetrically scaled volume of the secondary side of the EPR steam generator. The secondary side includes feedwater injection systems for the both steam generators. From the secondary side, the steam flows to the atmosphere.

The laboratory building sets some limitations on the precise scaling of the steam generators. Hence, the height of the PWR PACTEL steam generators is about $1 / 4$ of the height of 
TABLE 3: PWR PACTEL characteristics.

\begin{tabular}{|c|c|c|}
\hline Characteristics & PWR PACTEL & $\begin{array}{l}\text { PWR/EPR } \\
\text { (Olkiluoto 3) }\end{array}$ \\
\hline Reference power plant (loops and steam generators) & PWR/EPR & - \\
\hline Volumetric scale ${ }^{(1)}$ : pressure vessel/steam generators/pressurizer & $1: 405 / 1: 400 / 1: 565$ & - \\
\hline $\begin{array}{l}\text { Height scale }{ }^{(1)} \text { : pressure vessel (core; relative elevation)/steam } \\
\text { generators/pressurizer }\end{array}$ & $1: 1 / 1: 4 / 1: 1.6$ & - \\
\hline Number of primary loops & 2 & 4 \\
\hline Steam generator type & Vertical & Vertical \\
\hline Maximum heating power ${ }^{(1)}$ — thermal power $[\mathrm{MW}]$ & 1 & 4300 \\
\hline Number of rod simulators ${ }^{(1)}$ —fuel rods & 144 & 63865 \\
\hline Heated length of rod simulators ${ }^{(1)}$ —active core height $[\mathrm{m}]$ & 2.42 & 4.2 \\
\hline Axial power distribution ${ }^{(1)}$ & Chopped cosine & - \\
\hline Maximum cladding temperature ${ }^{(1)}\left[{ }^{\circ} \mathrm{C}\right]$ & 800 & - \\
\hline Maximum operating pressure ${ }^{(1)}$ —operational/design pressure $[\mathrm{MPa}]$ & 8.0 & 15.5/17.6 \\
\hline Maximum operating temperature ${ }^{(1)}$-inlet/outlet coolant temperature $\left[{ }^{\circ} \mathrm{C}\right]$ & 300 & $296 / 329$ \\
\hline Maximum secondary pressure—design secondary pressure $[\mathrm{MPa}]$ & 5.0 & 10 \\
\hline Maximum secondary temperature-design secondary temperature $\left[{ }^{\circ} \mathrm{C}\right]$ & 260 & 311 \\
\hline Main material of components & Stainless steel & - \\
\hline Insulation material & $\begin{array}{c}\text { Mineral wool } \\
\text { (Aluminium cover) }\end{array}$ & - \\
\hline Steam generator U-tube diameter/thickness [mm] & $19.05 / 1.24$ & $19.05 / 1.09$ \\
\hline Average steam generator U-tube length [m] & 6.5 & - \\
\hline Number of U-tubes in steam generator & 51 & 5980 \\
\hline Number of instrumented U-tubes in steam generator $1 /$ steam generator $2^{(3)}$ & $8 / 14\left(51^{(3)}\right)$ & - \\
\hline
\end{tabular}

the EPR steam generators. Therefore, the volumetric scaling approach is not fully attained.

The instrumentation of the loops and especially of the primary side U-tubes is considerably extensive. Altogether about 250 temperature, pressure, and differential pressure measurement transducers are attached to allow deeper analysis of steam generator behaviour. Table 3 presents PWR PACTEL characteristics in brief. A schematic view of a PWR PACTEL steam generator is shown in Figure 5. The facility description of PWR PACTEL can be found in [5], and the facility characteristics are also discussed in [6].

3.2. PWR PACTEL Experiments. The characterizing experiments including pressure and heat loss, natural circulation, and steam-generator feedwater system-related experiments have been carried out. From this series one SBLOCA experiment was chosen to be the basis for the PWR PACTEL benchmark exercise described in the next chapter. This first experiment series, was designed to determine the behaviour of the facility and the steam generators.

PWR PACTEL offers a possibility to carry out experiments with large flexibility. The new different scale compared to the other PWR test facilities offers yet another prospect for future research activities. PWR PACTEL, a new setup in the scenery of thermal-hydraulic test facilities, offers also another viewpoint to code validation processes.

3.3. PWR PACTEL Benchmark Exercise. The PWR PACTEL benchmark exercise is organized in Lappeenranta, Finland by Lappeenranta University of Technology (LUT). It is presented in more detail in reference [12]. This benchmark gives a unique opportunity for system code users to participate in an exercise where they can model a new facility configuration. The PWR PACTEL benchmark was launched in 2010 as part of the PWR PACTEL facility introduction.

The chosen transient for the PWR PACTEL benchmark is a small break loss-of-coolant accident (SBLOCA) case. This experiment (SBL-50) is discussed by Riikonen in [13]. The results of the first phase of the benchmark, that is, blind calculations, are available in [12]. As an example of the benchmark experiment, Figure 6 presents primary and secondary pressure progression in PWR PACTEL during the transient.

The first benchmark workshop, where the blind calculation case was introduced and discussed, was held 5th of October 2010. Seven organizations from Czech Republic, Germany, Italy, Sweden, and Finland participate to the benchmark exercise, and they utilize four different system codes 


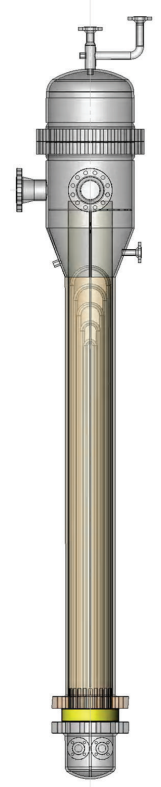

Figure 5: PWR PACTEL steam generator.

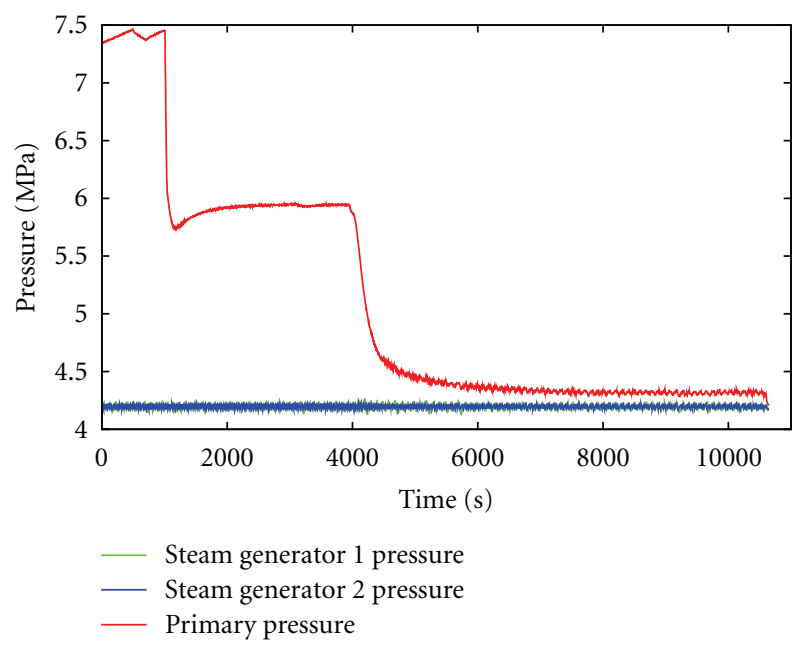

Figure 6: Primary- and secondary-side pressures in PWR PACTEL benchmark experiment.

within the exercise case. The blind calculation work was followed by an open calculation exercise. The second workshop was held in May 2011 in Lappeenranta, Finland.

\section{Conclusions}

In Finland, own research and continuous development of know-how has always been part of the national nuclear safety concept, especially when connected with the specific nuclear power plant types operated in Finland. Both PACTEL and PWR PACTEL have been constructed partly for this purpose for the field of experimental thermal-hydraulic research. PACTEL was designed particularly for VVER studies and PWR PACTEL especially for EPR specifics with focus on the vertical steam generator behaviour. Considering the future research activities, both facility setups are maintained and kept in a fully operational status.

The PACTEL facility was originally designed to model the thermal-hydraulic behaviour of VVER-440-type reactors. The facility consists of reactor pressure vessel parts, three loops with horizontal steam generators, a pressurizer, and emergency core cooling systems. The facility has been utilized in miscellaneous applications and experiments, for example, in the OECD International Standard Problem ISP33. More than 200 experiments have been conducted with the PACTEL test facility. PACTEL has been upgraded and modified on a case-by-case basis.

The latest configuration of PACTEL is the PWR PACTEL facility that has been constructed for EPR studies. A significant design basis is the utilization of some parts of PACTEL. At the same time, the focus was set on a proper construction of two new loops and vertical steam generators with an extensive instrumentation. The PWR PACTEL benchmark exercise was launched in 2010 with a small break loss-ofcoolant accident test as the chosen transient. PWR PACTEL is an excellent example of the PACTEL facility entity of being multifaceted and giving possibilities to carry out experiments with large flexibility. The new different scale of PWR PACTEL compared to the other PWR test facilities offers yet another prospect for future research activities. PWR PACTEL, a new configuration in the scenery of thermalhydraulic test facilities, offers also another viewpoint to code validation processes.

\section{Acknowledgments}

The planning and construction of the PACTEL facility was organized in 1990 by Technical Research Centre of Finland (VTT) in cooperation with LUT. Financial support at the time was provided by the Ministry of Trade and Industry, VTT and LUT. Along the years, support for the PACTELrelated experimental activities at LUT has been provided by power companies and other organizations. The planning and construction work for PWR PACTEL was performed at Lappeenranta University of Technology by the Nuclear Safety Research Unit. Financial support for the construction and commission of the test facility has been provided by the Finnish Funding Agency for Technology and Innovation (Tekes) and the Finnish power companies Teollisuuden Voima Oyj (TVO) and Fortum Oyj. PWR PACTEL-related experimental activities at LUT are continuing in 2011 under the PAX project within the Finnish Research Programme on Nuclear Power Plant Safety 2011-2014 (SAFIR2014).

\section{References}

[1] H. Purhonen, Experimental Thermal Hydraulic Studies on the Enhancement of Safety of LWRs, vol. 293, Acta Universitatis Lappeenrantaensis, Lappeenranta, 2007.

[2] H. Purhonen, M. Puustinen, V. Riikonen, R. Kyrki-Rajamäki, and J. Vihavainen, "PACTEL integral test facility-description of versatile applications," Annals of Nuclear Energy, vol. 33, no. 11-12, pp. 994-1009, 2006. 
[3] H. Purhonen, M. Puustinen, V. Riikonen, R. Kyrki-Rajamäki, and J. Vihavainen, "PACTEL-a versatile facility for research of thermal hydraulics," in Proceedings of the 11th International Topical Meeting on Nuclear Reactor Thermal-Hydraulics (NURETH-11), Popes' Palace Conference Center, Avignon, France, October 2005.

[4] J. Tuunanen, J. Kouhia, H. Purhonen et al., General description of the PACTEL test facility, VTT Research Notes, 1929. 35 p. + app. 75 p. VTT Technical Research centre of Finland, Espoo, 1998.

[5] V. Riikonen, V. Kouhia, A. Räsänen, and H. Partanen, "General description of the PWR PACTEL test facility," Tech. Rep. number, Lappeenranta University of Technology, Nuclear Safety Research Unit, YTY 1, Lappeenranta, 2009.

[6] A. Rantakaulio, V. Kouhia, V. Riikonen et al., "A new integral facility PWR PACTEL for vertical steam generator simulation," in Proceedings of the International Congress on Advances in Nuclear Power Plants (ICAPP '10), pp. 13.6-17.6, San Diego, California, USA, 2010.

[7] H. Purhonen, J. Kouhia, and H. Holmström, ISP-33 OECD/ NEA/CSNI International Standard Problem No. 33 (ISP 33), PACTEL Natural Circulation Stepwise Coolant Inventory Reduction Experiment. Comparison Report, Volumes I and II (December 1994), VTT Energy, Nuclear Energy, 1994.

[8] H. Purhonen, J. Kouhia, and H. Kalli, "ISP-33 Standard problem on the PACTEL facility," in Proceedings of the 7th International Topical Meeting on Nuclear Reactor Thermal Hydraulics, NURETH-7, vol. 3, pp. 2146-2158, Saratoga Springs, New York, USA, September 1995.

[9] OECD, CSNI Integral Test Facility Validation Matrix for the Assessment of Thermal-Hydraulic Codes for LWR LOCA and Transients, OECD, Paris, France, 1996.

[10] OECD/NEA, "Validation matrix for the assessment of thermal-hydraulic code validation matrix," Tech. Rep. NEA/CSNI/ R, OECS Support Group on the VVER Thermal-Hydraulic Code Validation Matrix, Paris, France, 2001.

[11] J. Vihavainen, V. Riikonen, and R. Kyrki-Rajamäki, “TRACE code modeling of the horizontal steam generator of the PACTEL facility and calculation of a loss-of-feedwater experiment," Annals of Nuclear Energy, vol. 37, no. 11, pp. 1494 1501, 2010.

[12] V. Riikonen and V. Kouhia, "Summary report of PWR PACTEL benchmark experiment blind calculations," Tech. Rep. PAX 1, Lappeenranta University of Technology, Nuclear Safety Research Unit, Lappeenranta, 2011.

[13] V. Riikonen, "Natural circulation experiments with PWR PACTEL facility," type YTY 3, Lappeenranta University of Technology, Nuclear Safety Research Unit, Lappeenranta, 2010. 

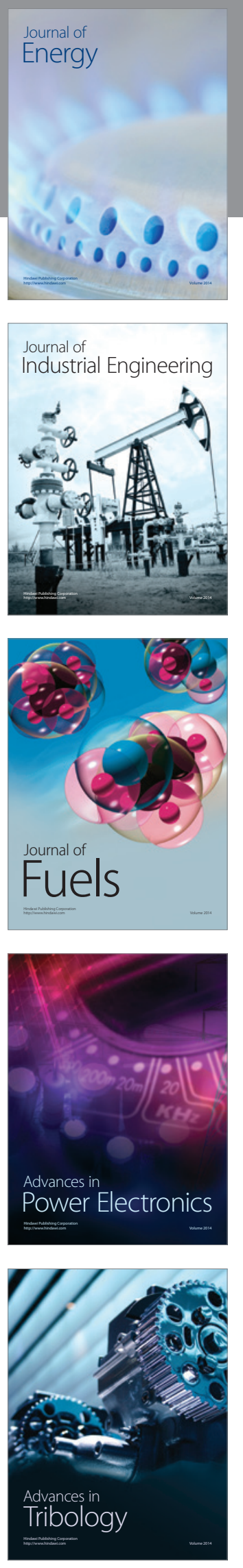
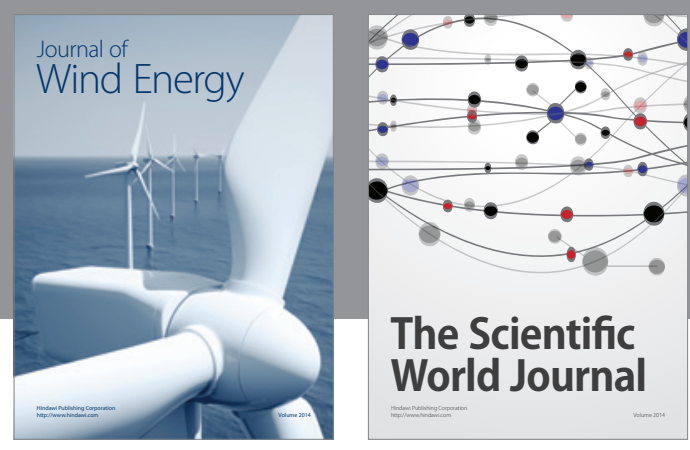

The Scientific World Journal

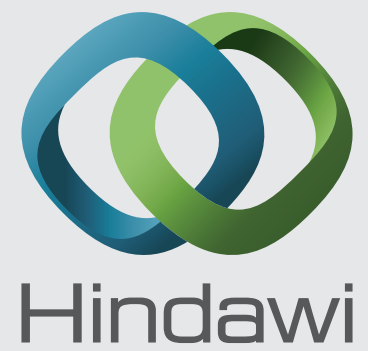

Submit your manuscripts at http://www.hindawi.com
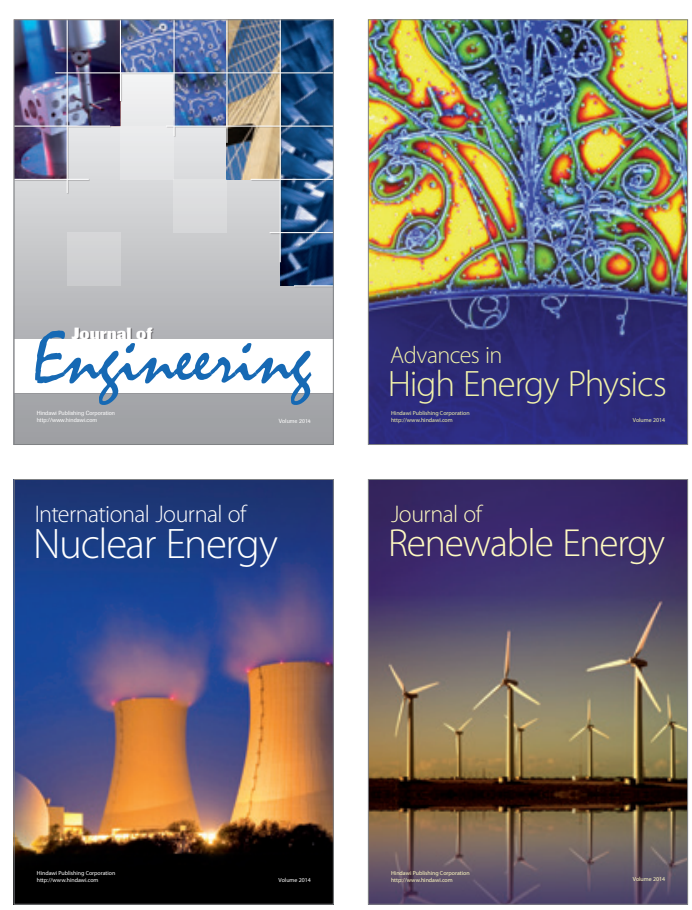

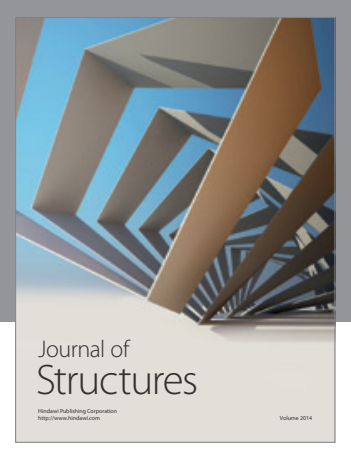

Rotating
Mechinery
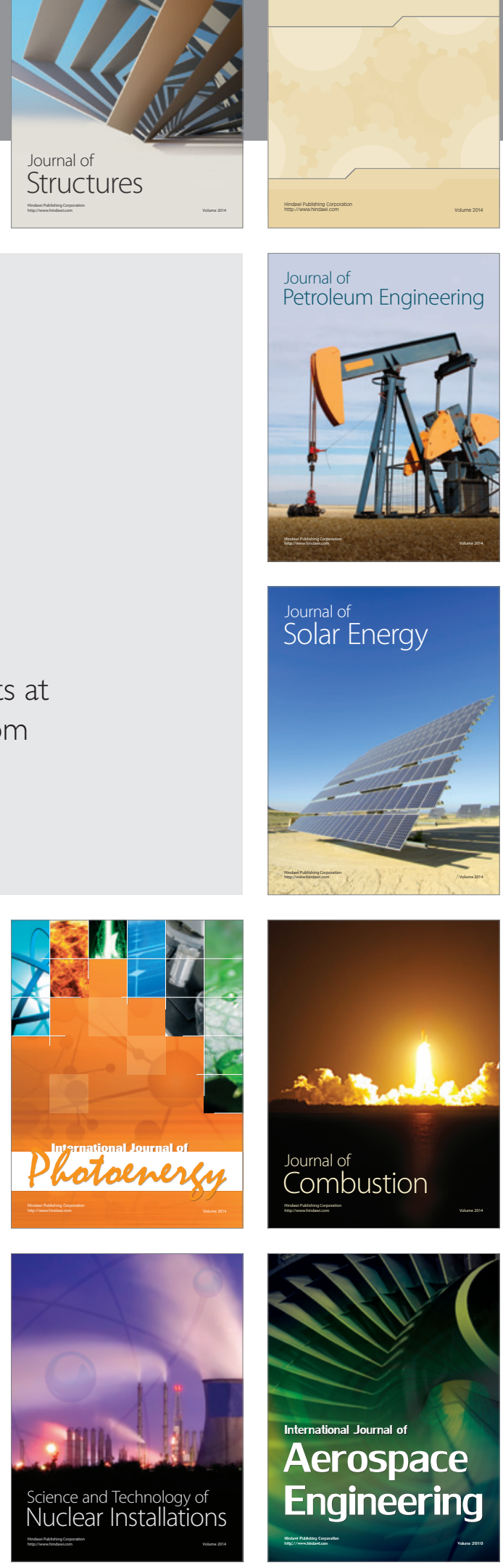